\title{
A IMPLEMENTAÇÃO DE POLÍTICAS PÚBLICAS DE INGRESSO NO ENSINO SUPERIOR E A JUDICIALIZAÇÃO DO SISTEMA DE COTAS NA UNIVERSIDADE FEDERAL DA BAHIA
}

Isabel Bezerra de Lima Franca

\section{INTRODUÇÃO}

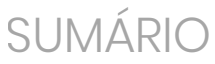

A Constituição Federal de 1988, ao prever normas de cunho programático, deixou para o legislador ordinário a tarefa de regular essas políticas, vinculando à administração a sua implementação e, ao mesmo tempo, atribuindo ao Poder Judiciário o controle e a fiscalização desse processo. Essa nova dinâmica desencadeou um processo de judicialização que levou muitos atores ao Judiciário em busca da implementação de políticas públicas ou para corrigir o rumo daquelas que haviam sido implementadas, principalmente nos serviços sociais de saúde e educação (AVRITZER; MARONA, 2014).

No ensino superior, a partir de 1999, as disposições da Lei de Diretrizes e Bases da Educação (LDB), Lei n. 9.394/1996, começaram a produzir efeitos propiciando a formulação e implementação de diversas políticas públicas para fomentar o ensino superior nas universidades federais. A partir de 2003, no governo do Presidente Luiz Inácio Lula da Silva, esse processo atinge seu ápice com a implementação de diversas políticas públicas voltadas ao financiamento das ações de ensino em instituições privadas, além de investimentos e incentivos para reestruturação e democratização das universidades federais (DE CARVALHO, 2014).

Nas universidades federais, essas políticas foram criadas por meio de Ações Afirmativas, cujo objetivo era sanar o grande déficit educacional que o Brasil tinha em relação a estudantes negros e pobres. Nesse sentido, as universidades federais passaram a receber incentivos para implementar políticas de inclusão social visando a democratizar 
esse nível de ensino. Contudo, o processo de implementação dessas políticas públicas não foi pacífico, pois as primeiras universidades que implementaram tais políticas optaram por criar cotas raciais subtraindo vagas do seu processo seletivo regular, provocando reações em razão da insuficiência do número de vagas (APRILE; BARONE, 2009).

A Universidade Federal da Bahia (UFBA) foi a terceira universidade federal a implementar uma política pública de ingresso, sendo a Universidade de Brasília (UnB) a primeira e a Universidade Federal do Paraná (UFPR) a segunda (MULHOLLAND, 2006). No entanto, essas universidades instituíram como critério para participação no sistema de cotas a condição de afrodescendente, enquanto a UFBA, ciente de a população da Bahia ser composta na maior parte por afrodescendentes, decidiu adotar como filtro preliminar os estudantes de escola pública para a partir daí adotar o critério racial. Assim, depois de um conturbado processo decisório, o sistema de cotas da UFBA começou a ser implementado provocando um aumento substancial nas ações judiciais de estudantes contra a universidade, pois tanto alunos favoráveis à medida quanto contrários a ela passaram a disputar seu ingresso na universidade por meio do Judiciário (SANTOS, 2012).

Diante disso, esse trabalho buscou, por meio da análise das decisões judiciais do Tribunal Regional Federal da 1a Região (TRF1), verificar o processo de judicialização da implementação da política de cotas na UFBA, visando a conhecer os argumentos utilizados pelos alunos para justificarem seus pedidos bem como os fundamentos utilizados pelo Judiciário para o seus deferimento ou indeferimento. Para isso, a pesquisa utilizou o banco de dados do TRF1 a fim de, em primeiro lugar, conhecer os temas discutidos nos tribunais e em seguida, o site do Conselho da Justiça Federal para analisar as ementas da jurisprudência unificada desse órgão sobre esses temas. Assim, o trabalho foi dividido em três partes: a primeira discorrendo sobre as políticas públicas de ensino, a segunda sobre o processo decisório da implementação da política de cotas na UFBA e a terceira apresentando um levantamento dos processos contra a universidade e os fundamentos das decisões judiciais. 


\section{A EDUCAÇÃO SUPERIOR E AS POLÍTICAS PÚBLICAS DE DEMOCRATIZAÇÃO DO ENSINO}

Nas últimas décadas, o Brasil passou por diversas transformações na área de educação, visto que a ênfase dada ao direito à educação na Constituição de 1988 foi reforçada pelas recomendações da Organização das Nações Unidas para a Educação, a Ciência e a Cultura (Unesco) ${ }^{1}$ e por uma política de incentivos gerenciadas pelo Banco Mundial (WARDE, 1996).

Embora a Constituição Federal de 1988 apresente poucos artigos disciplinando a educação superior, referindo-se apenas à autonomia universitária e à indissociabilidade do ensino, pesquisa e extensão, remeteu à legislação ordinária a regulamentação das normas relativas ao ensino superior, de modo que, essa aparente deficiência acabou compensada pela ampliação desses dispositivos na LDB (MOROSINI; FRANCO; SEGENREICH I, 2011).

Segundo Ranieri (2010), existem diversas diferenças nas normas contidas na Constituição Federal de 1988 em relação ao ensino básico e ao ensino superior, pois, para o primeiro, ela preconizou a universalização do ensino, por considerá-lo direito público subjetivo cuja ausência de implementação caracteriza omissão do poder público, enquanto em relação ao segundo delegou sua normatização à legislação ordinária. Dessa forma, a fruição do direito à educação no ensino superior, especialmente por parte da população que possui dificuldade de acesso a esse nível de ensino, dependia da implementação de políticas públicas que possibilitassem a democratização da educação superior, especialmente nas instituições públicas (CAÔN; FRIZZO, 2010).

Nesse sentido, diante da relevância das políticas públicas para a fruição do direito à educação, torna-se essencial apresentar um conceito de políticas públicas, que delimite seu âmbito de atuação. Assim, para Gavilanes (2010, p. 156),

\footnotetext{
${ }^{1}$ A Organização das Nações Unidas para a Educação, a Ciência e a Cultura (Unesco) foi constituída depois da Segunda Guerra Mundial com o propósito de contribuir para a construção da paz mundial. Suas áreas de atuação compreendem a área da educação, das Ciências Naturais, Humanas e Sociais, da cultura, da comunicação e informação e conta com a participação de mais de 190 Estados-membros (UNESCO, 2019).
} 
[...] política pública es un proceso integrador de decisiones, acciones, inacciones, acuerdos e instrumentos, adelantado por autoridades públicas con la participación eventual de los particulares, y encaminhado a solucionar o prevenir una situación definida como problemática. La política pública hace parte de un ambiente determinado del cual se nutre y al cual pretende modificar o mantener.

Esse autor apresentou quatro elementos essenciais para compor o conceito de políticas públicas: o primeiro, um processo integrador de decisões, ações, omissões, acordos e instrumentos; o segundo, um processo promovido pelas autoridades públicas com a participação eventual de indivíduos sociais; o terceiro, um processo para evitar ou reestabelecer uma situação definida como problema e o quarto, a natureza da política pública enquanto parte de um determinado ambiente no qual ela atua alterando ou mantendo seu status quo (GAVILANES, 2010).

Gavilanes (2010) chama a atenção para esses elementos enfatizando que não se pode perder a noção de políticas públicas de forma abrangente, pois essa classificação apesar de trazer uma noção descritiva não apresenta uma visão normativa, de modo que a definição proposta por ele reconhece $o$ aspecto político da política pública, porém não confunde esses dois elementos que ela apresenta. Para o autor, a palavra "política" expressa a arte e a ciência de governar visando a adquirir poder na tomada de decisões para produzir consenso. Por essa razão, o processo de decisão política se torna muito abrangente, englobando ações, omissões, acordos e instrumentos impulsionados pelas autoridades públicas, cujo intuito é resolver ou prevenir situações definidas como problemáticas.

Diante disso, o conceito desenvolvido por Parada (2002, p. 13) define implementação de políticas públicas como "[...] o conjunto deliberado e sequencial de atividades governamentais voltadas a alcançar metas e objetivos de uma política, visando a transformar os objetivos em resultados". Esse conceito permite considerar maior número de elementos porque engloba todo o ciclo das políticas públicas.

No mesmo sentido, Subirats (1994) afirma que não se pode bloquear o conceito de política pública, considerando-o exclusivamente 
por uma ótica positiva, já que no discurso de Heclo (1981) a política pública também engloba atividades passivas nas quais os policy makers podem decidir que a melhor opção para o momento é não fazer nada.

De acordo com Subirats (1994), reconhecer esse tipo de ausência de decisão é um fator essencial para a construção de "agendas" ou programas de ação pública. Em vista disso, a inclusão na análise de políticas públicas dos impactos ou resultados não esperados como os efeitos da política que podem ser desencadeados em seu processo de implementação devem ser contingenciados.

Embora as políticas públicas apresentem essa característica abrangente, pode se afirmar que foi o seu aspecto ativo que tornou possível a implementação dos programas e políticas públicas descritos nas disposições da LDB, aspecto esse justificado por Cury (1997) pelo fato do grande número de dispositivos relativos ao ensino superior, englobando desde o artigo 43 até o 57, representando 16,3\% do total dos 92 artigos contidos nessa legislação.

Conforme esse autor, os dispositivos trazidos pela Lei $\mathrm{n}$. 9.394/1996 se assentaram em duas prerrogativas: a primeira representada por conferir maior autonomia às instituições de ensino superior e a segunda, por acrescentar maior flexibilidade a essa atuação. Assim, enquanto "[...] os artigos 43-50 se ocupam da educação superior de modo geral, os restantes se encarregam da prerrogativa Universitária" (CURY, 1997, p. 12).

Em vista disso, depois da edição da LDB, foram criados diversos instrumentos normativos para implementar suas disposições, especialmente no governo do Presidente Lula, propiciando uma clara expansão no ensino superior público (DE CARVALHO, 2014).

Segundo De Carvalho (2014), a política de expansão e financiamento do ensino superior promovida nos dois mandatos do Presidente Lula (2003-2010) obteve prioridade na agenda governamental porque foi articulada com base em programas assentados sobre dois eixos: o primeiro com base no aumento da oferta de ensino por meio de expansão das universidades federais por meio do programa de Reestruturação e Expansão das Universidades Federais (Reuni) e do Plano 
Nacional de Assistência Estudantil (PNAES) - e o segundo, visando ao aumento da oferta de ensino por meio de financiamento em instituições de ensino privadas pelo Fundo de Financiamento Estudantil (FIES) e pelo Programa Universidade para Todos (Prouni).

O Reuni foi instituído pelo Decreto n. 6.096, de 24 de abril de 2007, e teve como principal objetivo ampliar o acesso e a permanência na educação superior, criando condições, no nível de graduação, para melhor aproveitamento tanto por meio da estrutura física das universidades, quanto dos recursos humanos existentes nelas.

No mesmo sentido, o PNAES foi criado como uma política pública do Ministério da Educação (MEC) que visa a auxiliar a permanência de jovens de baixa renda matriculados em cursos de graduação presencial nas Instituições Federais de Ensino Superior (IFES) (ZAGO, 2006). Segundo o artigo 20 do Decreto n. 7.234, de 19 de julho de 2010, são objetivos do PNAES:

I - democratizar as condições de permanência dos jovens na educação superior pública federal; II - minimizar os efeitos das desigualdades sociais e regionais na permanência e conclusão da educação superior; III - reduzir as taxas de retenção e evasão; e IV - contribuir para a promoção da inclusão social pela educação. (BRASIL, 2010).

Além do Reuni e do PNAES, outras alterações importantes relacionadas à expansão do ensino superior decorreram da edição das seguintes leis: Lei n. 10.260/2001, que regulamentou o FIES e Lei $n$. 11.096/05, que instituiu o Prouni. O FIES, criado em 2001, foi totalmente reestruturado em 2005, para como o Prouni, ampliar o número de estudantes beneficiados.

No setor privado, o Prouni se tornou a principal iniciativa do governo federal para facilitar o acesso de alunos carentes ao ensino superior. Criado em 2004, oferecia bolsas de estudos de $50 \%$ ou de $100 \%$ na mensalidade em faculdades particulares aqueles que não conseguiram entrar em uma instituição pública (CATANI et al., 2006). 
No entanto, é possível afirmar que uma das medidas mais importantes para a democratização e expansão do ensino superior foi a concessão de incentivos para que as universidades federais públicas adotassem políticas compensatórias para permitir o acesso de uma parcela da população que não possuía meios nem condições de ingressar em uma universidade pública (CAÔN; FRIZZO, 2010).

No entanto, esse processo de democratização do ensino superior por meio de políticas públicas foi instituído de acordo com a autonomia universitária, permitindo que cada universidade implementasse suas políticas segundo sua disponibilidade, pois, de acordo com o artigo 207 da Constituição Federal de 1988, “[...] as universidades gozam de autonomia didático-científica, administrativa e de gestão financeira e patrimonial, e obedecerão ao princípio de indissociabilidade entre ensino, pesquisa e extensão" (BRASIL, 1988, art. 207, caput.).

Diante disso, verifica-se que embora o processo de implementação da política de cotas se deu respeitando a autonomia universitária, a ausência de critérios claros para enquadramento dos estudantes estabelecidos pela universidade pode ser considerado um dos fatores que contribuíram para desencadear o processo de judicialização que ocorreu no período da implementação da política pública em análise.

\section{A IMPLEMENTAÇÃO DE POLÍTICAS PÚBLICAS E A CRIAÇÃO DAS COTAS NA UFBA}

O campo de implementação de políticas públicas é recente, visto que seus estudos datam de aproximadamente 30 anos. No entanto, a análise da implementação de políticas públicas vem ocorrendo sob diversas perspectivas, englobando estratégias e metodologias diferentes em suas áreas temáticas, proporcionando uma ampliação nos padrões de avaliação e na delimitação de seus conceitos (WINTER, 2012).

De acordo com Winter (2012), os estudos sobre implementação, apesar de relativamente novos, vêm contribuindo para acrescentar novas perspectivas a abordagem de políticas públicas, porque na medida em que colocam o foco no fazer, permitem avaliar como elas são transformadas 
no processo de execução, revelando muitas barreiras e fatores que podem alterar o seu sucesso.

O autor afirma que, embora precisemos de mais pesquisas sobre o design de políticas públicas e os resultados de sua implementação, a utilização de um processo para explicar variações na implementação exige a combinação de três perspectivas teóricas diferentes: “[...] uma teoria sobre a definição de metas, uma teoria sobre o desempenho e uma teoria sobre a relação entre a definição de metas e o desempenho" (WINTER, 2012, p. 77). Pois, do contrário, generalizações na análise dos resultados de uma política pública podem acarretar sua invalidade por permitir relativizações nessa avaliação.

Segundo Matland (1995), na medida em que as pesquisas sobre implementação evoluíram, duas escolas de pensamento se desenvolveram como modelos para estudar e descrever o processo de implementação: o modelo top-down e o bottom-up. Contudo, esses modelos receberam diversas críticas e, em razão disso, foram feitas inúmeras tentativas para combinar essas duas principais perspectivas a fim de criar outras sobre a implementação.

A abordagem top-down recebeu três espécies de críticas: a primeira devido à utilização de linguagem estatutária como ponto de partida; a segunda em razão de a execução ser vista como um processo puramente administrativo, ignorando os aspectos políticos ou tentando eliminá-los; e a terceira por dar ênfase exclusiva aos arquitetos dos estatutos considerando-os atores-chave. Dessa forma, os modelos topdown, acabam vendo os atores locais como impedimentos para uma implementação bem-sucedida, ou seja, agentes cujo comportamento precisa ser controlado (MATLAND, 1995).

Os modelos bottom-up argumentam que os objetivos, estratégias, atividades e contatos entre os atores envolvidos na implementação devem ser compreendidos para entender os fatores que interferem nesse processo. Por essa razão, os estudos sobre os "burocratas no nível de rua"”

\footnotetext{
${ }^{2}$ Burocratas de nível de rua refere-se ao termo "Street-level bureaucrac" criado por Michael Lipsky para designar o papel dos burocratas no atendimento a sociedade quando sua posição permite grande discricionariedade nessa atuação.
} 
representam um dos principais estudos relacionados a essa abordagem. Em vista disso, a influência da política sobre a ação dos "burocratas de nível de rua" deve ser avaliada a fim de que se possa prever o efeito da política pública que está sendo avaliada (LIPSKY, 2010).

As críticas a esse modelo são de duas ordens: uma normativa, outra metodológica. A normativa aponta que em um sistema democrático, o controle político deve ser exercido por atores cujo poder deriva da capacidade de sua prestação de conta aos eleitores e o burocrata não tem legitimidade porque não foi eleito. A crítica metodológica enfatiza o nível de autonomia local, pois as variações decorrentes das ações podem ser explicadas pelas diferenças de autonomia em nível local (WEATHERLEY; LIPSKY, 1977).

Os desacordos acerca dessas abordagens levaram ao desenvolvimento de formas de análise com base na teoria organizacional, nas quais os teóricos passaram a verificar como a "ambiguidade e o conflito" afetavam a implementação das políticas. Por meio desses elementos, podem ser feitas previsões verificáveis sobre como o processo de implementação se desenvolverá, principalmente, quando há conflitos substanciais e uma política ambígua, em que tanto o modelo top-down quanto bottom-up têm alguma relevância.

No entanto, para Matland (1995), a ambiguidade não deve ser vista como uma deficiência em uma política, pois não é nem um mal nem um bem, apesar de muitas vezes causar falhas em sua implementação, mas apenas uma característica da política, sem que a isso se possa atribuir qualquer valor normativo.

Nesse sentido, as ambiguidades que envolveram o processo decisório para a implementação do sistema de cotas na UFBA demonstraram que a medida não foi isenta de conflitos, pois, apesar de esses fatores terem causado considerável atraso na execução da política, não afetaram substancialmente o resultado dela, contribuindo para a alteração do status quo na educação superior.

A UFBA foi a terceira universidade federal a implementar uma política de cotas e, no levantamento dos processos da universidade, verificou-se que houve um aumento substancial nas ações judiciais de 
estudantes que levou alunos favoráveis e contrários à política a disputarem seu ingresso na universidade por meio do Judiciário (MATTOS, 2006).

Nesse aspecto, a implementação de ações afirmativas na UFBA se mostrou conturbada desde o início do processo decisório, pois, segundo Santos (2012), em 2002, o grupo de trabalho constituído para estudar e sistematizar a implementação da política, apresentando propostas para as estratégias de inclusão social, não conseguia entrar em acordo. Diante disso, o grupo de trabalho responsável por esse processo promoveu uma intensa troca de e-mails com a comunidade acadêmica, porque ela, também, se encontrava dividida em posições antagônicas que acarretava, por um lado, defesas acirradas às cotas raciais e por outro, posições extremamente contrárias a elas (SANTOS, 2012).

Por fim, o Grupo de Trabalho pesquisou outras universidades que já haviam implementado a política de cotas, como a UnB, a UFPR e a Universidade Estadual do Mato Grosso do Sul (UEMS) a fim de verificar os problemas que a implementação das cotas haviam acarretado para apresentar aos Conselhos Superiores uma proposta que fosse aprovada ainda em 2004 para ingresso no vestibular de 2005 (SANTOS, 2012).

O resultado desse levantamento resultou na criação de um projeto denominado "Programa de Ação Afirmativa" na UFBA, uma versão preliminar de 18 de junho de 2003 da política pública para ser apresentada pelo pró-reitor de Graduação ao Conselho da universidade. Segundo Santos (2012, p. 43), esse projeto trazia propostas de ações de inclusão que foram divididas em quatro eixos: preparação, ingresso, permanência e pós-permanência.

A partir daí, em 3 de outubro de 2003, foi estabelecido um calendário temático compostos desses quatros eixos definindo debates sobre os seguintes aspectos: sub-representação dos negros e dos estudantes de escolas públicas no ensino superior público; necessidade de reserva de vagas para negros e/ou estudantes de escola pública; “[...] a questão do mérito versus a inclusão social; a questão da permanência; além de pontos relacionados pós-graduação e a inclusão social" (SANTOS, 2012, p. 48). 
No entanto, o eixo das discussões girava em torno da decisão entre cotas raciais ou socioeconômicas, por essa razão a universidade elaborou um questionário socioeconômico visando a angariar dados para auxiliar a tomada de decisão. Enquanto isso, o Programa "A Cor da Bahia" encaminhou à Reitoria da Universidade um pedido para que fosse incluído o quesito "cor" nesse questionário, argumentando sobre a necessidade de incorporar no estudo a reflexão sobre as relações raciais (SANTOS, 2012).

O estudo elaborado pelo Programa "A cor da Bahia" demonstrou que mais de $80 \%$ da população do estado era composta de afrodescendentes e em vista disso, a UFBA acabou optando por implementar cotas sociais para estudantes de escolas públicas e, somente a partir desse filtro, acrescentar um percentual para os estudantes de descendência negra (FERES; DAFLON; CAMPOS, 2011).

Dessa forma, a UFBA tornava-se a terceira universidade federal do País a implantar um sistema de cotas. Se a UnB decidiu por um percentual para candidatos negros, sem especificar a origem escolar, e a UFPR por percentuais distintos para negros e estudantes oriundos do sistema público, assim como vagas para indígenas, a UFBA implantou um sistema no qual a origem escolar - sistema público - era o ponto de partida, mas a partir disso, determinava um percentual para negros de $85 \%$ e outro para não negros de $15 \%$ (FERES; DAFLON; CAMPOS, 2011).

No entanto, a opção por esse filtro preliminar composto por estudantes de escolas públicas acabou sendo responsável por um aumento substancial nas ações contra a universidade, na medida em que alunos de escolas filantrópicas e comunitárias, por serem de origem pobre, também passaram a buscar o Judiciário solicitando a equiparação dessas escolas com as escolas públicas.

\section{A JUDICIALIZAÇÃO DA POLÍTICA DE COTAS NA UFBA}

O sistema de cotas para estudantes negros e/ou oriundos de escola pública foi a política pública que mais levou estudantes aos tribunais, 
especialmente no caso da UFBA, onde as cotas foram insuficientes e até mesmo alunos que ficaram acima da nota de corte não conseguiram ingressar na universidade no ano de criação da política pública.

Diante disso, esse trabalho procurou mapear os processos dessa universidade, mas em razão do grande número de processo, optou-se por contabilizar apenas intervalos regulares de 5 anos em 5 anos, a fim de verificar quais eram as solicitações feitas ao Judiciário e qual a posição deste. A pesquisa foi executada em dois bancos de dados: o primeiro, o site do TRF1, para onde são encaminhados os recursos das decisões relativas à UFBA, e o segundo, o site do Conselho da Justiça Federal (CJF), no qual pôde ser verificado o teor das ementas das decisões judiciais relativas aos processos de estudantes contra a universidade.

No primeiro banco de dados, a pesquisa retornou 512 processos, de 1999 a 2014, dentre os quais foi possível observar o assunto sob o qual o processo foi cadastrado, permitindo comparar ações de estudantes com outros temas, a fim de averiguar a evolução dessas ações, conforme demonstra o Gráfico 1.

Gráfico 1 - Comparativo entre ações de estudantes e outros processos na UFBA

\section{Ações da UFBA}

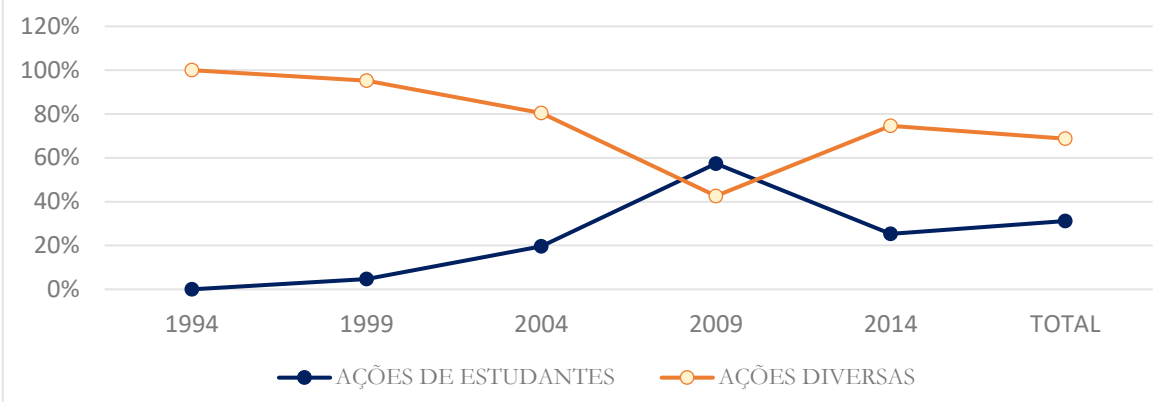

Fonte: Elaborado pela autora deste capítulo a partir de dados do CJF (19942014)

O Gráfico 1 apresenta, de acordo com os intervalos escolhidos nesta pesquisa, um número de ações 14 vezes maior no ano de 2009 em relação ao ano de 2004, demonstrando que, a partir de 2005, primeiro ano da implementação da política de cotas, houve um crescimento contínuo 
nos processos de estudantes. Dessa forma, de acordo com o Gráfico 1, pode-se observar que em 1999 as ações de estudantes praticamente não existiam, representando apenas 5\% do total de ações. Contudo, em 2009, essas ações equivaliam a $57 \%$ do total de processos, percentual esse que voltou a cair somente em 2014 para 25\% depois da Resolução n. 3, de 12 de novembro de 2012, da UFBA ter alterado o artigo 3 e o artigo 50 da Resolução n. 01/04 do CONSEPE visando a reduzir as controvérsias existentes em torno do termo "escola pública".

Depois do levantamento dos processos da UFBA no site do TRF1, utilizaram-se os temas encontrados como critério de busca para a jurisprudência do site do CJF, a fim de, por meio das ementas desse Conselho, verificar os pedidos que os estudantes levavam ao Judiciário e os argumentos dele para deferir ou indeferir tais pedidos. No site do CJF, foram analisadas 151 decisões judiciais proferidas pelo TRF1, nas quais foram observados os seguintes aspectos: se o tema das ações era condizente com o conteúdo discutido na ação judicial e se os pedidos relativos ao mesmo tema obtiveram respostas semelhantes do Judiciário (Tabela 1). Assim, a Tabela 1 apresenta uma divisão de assuntos discutidos nas ações de estudantes, localizados a partir do nome da UFBA e do tema localizado no campo assunto do TRF1 conferido a ação no momento de sua distribuição pela Secretaria desse Tribunal.

Tabela 1 - Classificação das ações de estudantes por assunto

\begin{tabular}{lrr}
\hline Tema das ações & Qtde. & $\%$ \\
\hline Ingresso no ensino superior & 4 & $3 \%$ \\
Lei de Cotas $\mathrm{n}^{\circ}$ 10.558/02 & 5 & $3 \%$ \\
Ensino fundamental e médio & 3 & $2 \%$ \\
Ensino superior & 2 & $1 \%$ \\
Jubilação & 1 & $1 \%$ \\
Matrícula & 128 & $85 \%$ \\
Transferência de estudante & 2 & $1 \%$ \\
Vestibular & 6 & $4 \%$ \\
\hline Total & $\mathbf{1 5 1}$ & $\mathbf{1 0 0 \%}$ \\
\hline
\end{tabular}

Fonte: Elaborada pela autora deste capítulo a partir de dados do CJF (1994-2014) 
Conforme a Tabela 1, cerca de $85 \%$ dos processos de estudantes encontrados nessa universidade foram intitulados como "Matrícula", mas isso não significa que todos os processos tratassem apenas de assuntos relacionados à matrícula, pois esse montante englobava desde os óbices para ingressos no ensino superior até problemas relacionados à permanência, materializados em impedimento à permanência em razão da jubilação do aluno ${ }^{3}$.

Dessa forma, apesar de o tema matrícula representar $85 \%$ dos processos encontrados, depois de verificar o teor das decisões judiciais, constatou-se que a maioria delas se referia, na verdade, aos critérios adotados pela universidade para implementação de sua política de cotas, já que, das 128 ações intituladas como matrículas, 108 delas discutiam os requisitos escolhidos para ingresso pelo sistema de cotas (Tabela 2).

Tabela 2 - Conteúdo discutido nas decisões intituladas Matrícula

\begin{tabular}{lrr}
\hline Matrícula & Qtde. & $\%$ \\
\hline Ausência de documentos & 6 & $4 \%$ \\
Grade de ensino & 1 & $1 \%$ \\
Jubilação & 1 & $1 \%$ \\
Disciplina pré-requisito & 1 & $1 \%$ \\
Processo seletivo de mestrado & 1 & $1 \%$ \\
Trancamento de matrícula & 1 & $1 \%$ \\
Transferência de estudante & 9 & $7 \%$ \\
Sistema de cotas & 108 & $84 \%$ \\
\hline Total & $\mathbf{1 2 8}$ & $\mathbf{1 0 0 \%}$ \\
\hline
\end{tabular}

Fonte: Elaborada pela autora a partir de dados do CJF (1994-2014)

Depois de uma segunda triagem a partir da leitura dos outros temas das ementas judiciais, considerando o teor das decisões a partir dos assuntos listados na Tabela 2, verificou-se que do total das 128 decisões judiciais, 122 tratavam especificamente da política de cotas que havia sido implementada na UFBA conforme pode ser observado na Tabela 3.

\footnotetext{
${ }^{3}$ Ação que consiste na perda do direito de se matricular num curso, normalmente universitário, por possuir muitas reprovações. Disponível em: https://www.dicio.com.br/jubilacao.
} 
Tabela 3 - Ações relativas à política de cotas da UFBA

\begin{tabular}{lrr}
\hline Sistema de cotas & Qtde. & \% \\
\hline Matrícula & 108 & $89 \%$ \\
Lei $10.558 / 02$ & 5 & $4 \%$ \\
Ingresso no ensino superior & 4 & $3 \%$ \\
Vestibular & 5 & $4 \%$ \\
\hline Total & $\mathbf{1 2 2}$ & $\mathbf{1 0 0 \%}$ \\
\hline
\end{tabular}

Fonte: Elaborada pela autora deste capítulo a partir de dados do CJF (1994-2014)

Esse montante de 122 decisões foi analisado e categorizado considerando-se os seguintes aspectos: se a parte era favorável ou contrária ao sistema de cotas; se favorável, qual o pedido elaborado ao Judiciário, qual o argumento utilizado para sustentar esse pedido, qual o provimento do Judiciário em relação a ele e qual a fundamentação desse órgão para conceder ou negar o pedido pleiteado na ação.

A análise das decisões judiciais demonstrou que $66 \%$ dos pedidos interpostos no Judiciário pertenciam a alunos favoráveis às cotas que buscavam seu enquadramento nos critérios elencados pela política pública e o restante, ou seja, 34\% foram processos interpostos por alunos contrários ao sistema de cotas que se sentiam prejudicados pela implementação dessa política.

No entanto, para analisar os pedidos desses alunos optou-se por fazer a separação considerando apenas os argumentos que eles utilizaram para justificar seu pedido ao Judiciário e não a posição deles em relação à política de cotas, pois a partir dos argumentos era possível observar a posição do Judiciário tanto em relação aos alunos contrários quanto aos favoráveis. Assim, conforme Tabela 4, os pedidos foram divididos em sete tópicos, de acordo com o argumento utilizado pelos alunos para solicitar sua matrícula ao Judiciário, discutidos a seguir. 
Tabela 4 - Assuntos discutidos nas decisões sobre política de cotas da UFBA

\begin{tabular}{rlrr}
\hline Item & Pedido do Aluno & Qtde. & $\%$ \\
\hline 1 & Conclusão do Enem & 4 & $3 \%$ \\
2 & Equiparação à escola pública & 65 & $53 \%$ \\
3 & Falta de vagas & 13 & $10 \%$ \\
4 & Aluno graduado & 2 & $2 \%$ \\
5 & Extinção do processo & 2 & $2 \%$ \\
6 & Preenchimento incorreto & 2 & $2 \%$ \\
7 & Resolução n. 1/04 da UFBA & 34 & $28 \%$ \\
\hline Total & $\mathbf{1 2 2}$ & $\mathbf{1 0 0 \%}$ \\
\hline
\end{tabular}

Fonte: Elaborada pela autora deste capítulo a partir de dados do CJF (1994-2014)

No primeiro tópico da Tabela 4, são encontradas quatro ações pleiteando o diploma de ensino médio, conforme regulamentado pela Portaria MEC n. 807/2010 que autoriza ao aluno maior de 18 anos a obter o certificado de conclusão de curso do ensino médio com base na nota obtida no Enem.

O item 2 apresenta 65 pedidos de equiparação de escolas privadas, cenecistas, comunitárias, filantrópicas e supletivos visando ao enquadramento do aluno no requisito: "estudantes que tenham cursado todo o ensino médio e pelo menos uma série entre a quinta e a oitava do ensino fundamental na escola pública"(UFBA, Resolução 01/04, p.1).

Esse item se mostrou muito controverso, pois, como a Resolução n. 01/2004 da UFBA não delimitava o universo da escola pública, a UFBA ficou à mercê do entendimento do Judiciário acerca dessa questão.

Nesse aspecto, haviam 36 pedidos de equiparação de supletivo público ao ensino médio regular, os quais o Judiciário deferiu $100 \%$ deles a favor do estudante sob o argumento de que o termo "escola pública" não diferenciava o ensino supletivo do ensino regular.

Nas outras 29 decisões, foram encontrados pedidos de equiparação de escolas cenecistas, filantrópicas comunitárias e particular subsidiadas por convênios celebrados com o poder público, além de pedidos de alunos que cursaram o ensino básico ou médio parcialmente 
em instituições privadas com bolsas de estudo. Nessas ações, a posição do Judiciário se mostrou muito dividida, pois, em $66 \%$ dos casos, os pedidos foram deferidos e em $34 \%$ indeferidos. Na fundamentação dessas decisões, verificou-se que, os juízes que decidiam considerando a hipossuficiência do aluno, deferiu o sistema de cotas mesmo que o estudante tivesse estudado alguns anos em escola particular como bolsista, enquanto que aqueles que olhavam apenas para a qualidade do ensino obtido negaram o ingresso pelo sistema de cotas, mesmo que o estudante tivesse frequentado a escola particular por falta de vagas na rede pública de ensino e seus estudos tivessem sido subsidiados pelo estado.

O terceiro item apresentou 13 ações de alunos que obtiveram nota acima da nota de corte do Enem, mas estavam acima do número de vagas. Nesses casos, os juízes deferiram o ingresso em $54 \%$ dos alunos, sob o fundamento de que os alunos que obtiveram nota suficiente para ingressar pelo sistema geral poderiam participar pela ampla concorrência, mesmo que tivesse se inscrito pelo sistema de cotas. No entanto, em $46 \%$ desses casos, os alunos tiveram seus pedidos indeferidos porque o Judiciário argumentou ausência de preenchimento dos requisitos para que o aluno pudesse participar por meio do sistema de cotas.

No quarto item, dois alunos tentaram ingressar por meio do sistema de cotas, mas, como já possuíam graduação anterior, seus pedidos foram indeferidos pelo Juiz sob o argumento de que o aluno graduado não se encontrava em situação de desvantagem para ingresso no ensino superior por meio de cotas.

O item 5 apresentou dois casos em que houve o processo foi extinto sem o julgamento do mérito: o primeiro, porque a universidade atendeu ao pedido do estudante, levando à perda do objeto da ação e, o segundo, porque o próprio aluno desistiu da matrícula que estava pleiteando.

No sexto item, dois alunos alegaram erro no preenchimento da ficha de inscrição e os pedidos foram deferidos porque o Tribunal entendeu que a retificação do formulário foi efetuada dentro do prazo previsto no edital. 
No último tópico, 34 alunos se insurgiram contra a Resolução n. 01/2004, publicada em julho de 2004 pela UFBA para regulamentar a política de cotas. Desse total, $50 \%$ dos estudantes argumentaram direito intemporal ${ }^{4}$ e outros, $50 \%$ discutiam a legalidade e/ou inconstitucionalidade da política, alegando que o sistema de cotas feria o Princípio Constitucional da Igualdade contido na Constituição Federal de 1988.

Nas ações alegando direito intemporal, os estudantes argumentaram que, como a normativa da UFBA fora publicada em junho de 2004, não poderia ser aplicada ao vestibular de agosto do mesmo ano, devendo, portanto, respeitar o prazo de vigência estabelecido pelo Decreto-lei n. 4.657/1942, que regulamenta as normas do Direito Brasileiro. Diante disso, o Judiciário deferiu 95\% dos pedidos, uma vez que, segundo ele, a não observância desse lapso temporal fere o Princípio da Segurança Jurídica. No entanto, os $5 \%$ cujo pedido foi indeferido argumentaram que

[...] tendo sido editada resolução para regulamentar o sistema de cotas pela autoridade competente com antecedência suficiente para que todos os candidatos tomassem ciência dos critérios que seriam adotados no vestibular seguinte, não há que se falar em ilegalidade do ato, tampouco na sua invalidação após os aprovados, dentro das vagas dos cotistas e das dos não cotistas, já estarem estudando. (BRASIL, 2007).

Em relação aos pedidos de inconstitucionalidade e/ou ilegalidade da Resolução n. 01/2004 da UFBA, as decisões sobre a matéria se dividiram, pois $65 \%$ das decisões deferiram os pedidos levando os membros do Tribunal a suscitarem um "incidente de inconstitucionalidade" ${ }^{5}$ para

\footnotetext{
${ }^{4} \mathrm{O}$ termo direito intemporal é utilizado no Direito para explicar a vigência da lei a partir de sua publicação. No caso da Resolução n. 1/2004 da Universidade Federal da Bahia (UFBA), se os alunos ingressassem por meio de cotas em agosto de 2004 a norma que regulamentava a política pública não teria completado o prazo exigido na lei para entrar em vigor.

${ }^{5} \mathrm{O}$ incidente de inconstitucionalidade pode ser suscitado por qualquer juiz ou tribunal para declarar a inconstitucionalidade de uma lei por meio do controle de constitucionalidade difuso, conforme artigo 97 da Constituição Federal de 1988.
} 
conceder uma liminar no processo que permitia o ingresso do aluno prejudicado, enquanto nos $35 \%$ restantes, os pedidos dos estudantes foram indeferidos porque o Judiciário considerou a política constitucional argumentando que as cotas representavam uma medida de equidade entre desiguais e portanto, não feria a igualdade expressa na Carta Magna.

Entretanto, mesmo depois da decisão do Supremo Tribunal Federal (STF) na Arguição de Descumprimento de Preceito Fundamental (ADPF) n. 186, de 31 de julho de 2009, declarando a constitucionalidade das normativas que regulamentavam os sistemas de cotas, em muitas decisões, o Tribunal foi obrigado a deferir o recurso do aluno que alegou inconstitucionalidade da Resolução n. 01/2004 porque o juiz de primeiro grau havia concedido uma medida liminar para o ingresso e, ao tempo do julgamento do recurso, o aluno já havia se formado, não restando ao TRF1 alternativa senão deferir o pedido alegando que a situação de fato havia se consolidado.

Apesar de ter ocorrido um atraso de seis meses na implementação da política pública da UFBA, já que pretendia iniciar as cotas de agosto de 2004, a universidade conseguiu implementar sua política de cotas para os ingressantes no início de 2005, embora grande parte dos estudantes aprovados por esse sistema não ter conseguido efetuar sua matrícula em razão da insuficiência de vagas destinadas à essa política.

\section{CONSIDERAÇÕES FINAIS}

Na redemocratização do Estado brasileiro, a implementação de políticas públicas desencadeou um processo de judicialização, que alterou as relações horizontais entre os três poderes. Esse processo encontrou respaldo principalmente nas políticas públicas de saúde e educação.

No ensino superior, embora o problema orçamentário também exista, na maior parte das vezes, o Judiciário foi acionado não antes da implementação das políticas públicas, mas no curso de sua implementação, pois a maioria das disposições constitucionais relativas a esse nível de ensino é constituída por normas programáticas, cuja inércia do administrador muitas vezes depende da legislação ordinária que fica a cargo do Legislativo. 
No entanto, a premente necessidade de conferir eficácia também a essas normas programáticas levou grupos de interesse e movimentos sociais a provocarem os órgãos jurisdicionais como forma de aumentar a pressão social para que fossem formuladas políticas públicas que possibilitassem o exercício desses direitos, além de buscarem, por meio deles, corrigir o curso das políticas existentes.

A implementação da política de cotas, a princípio, não exigiu um aporte orçamentário imediato, tendo em vista que as vagas destinadas às cotas nas universidades foram suprimidas daquelas que já existiam. No entanto, a manutenção desses estudantes passou a exigir aporte financeiro posterior para viabilizar sua permanência, daí a resistência por parte da universidade em implementar tais políticas.

Em vista disso, a resistência de determinados setores da sociedade desencadeou um processo de judicialização que até então as universidades não tinham experimentado. Nesse sentido, esta pesquisa constatou que a UFBA obteve um crescimento exponencial do número de ações que ela possuía, na medida em que os alunos favoráveis e contrários a políticas passaram a discutir os critérios de ingresso por meio do Judiciário. Isso pode ser explicado por dois aspectos. Em primeiro lugar, devido ao seu conteúdo polêmico de ações afirmativas e, em segundo lugar, porque as vagas destinadas às cotas foram suprimidas da concorrência geral, que por si só já eram insuficientes para absorver todos os alunos que se formavam no ensino médio, de modo que, com a implementação desse sistema, a disputa se tornou ainda mais acirrada.

Nesse aspecto, não se pode esquecer que esse processo foi desencadeado tanto por atores interessados em participar do sistema quanto por aqueles contrários à política, que buscaram por meio do Judiciário assegurar uma vaga em uma instituição pública de ensino. Além disso, o fato de a universidade utilizar o filtro de estudantes de escola pública como pré-requisito para as cotas raciais sem delimitar o conceito na Resolução n. 01/2004 permitiu que alunos de escolas privadas sem fins lucrativos e bolsistas buscassem a equiparação de sua condição ao requisito de escola pública.

No entanto, esta pesquisa constatou que demandas judiciais utilizando esse argumento perderam força a partir da publicação da Lei 
de Cotas, Lei n. 12.711, de 29 de agosto de 2012, uma vez que a UFBA adequou sua Resolução a essa Lei delimitando de forma precisa o conceito de escola pública. Apesar disso, até o momento de elaboração deste trabalho ainda é possível encontrar processos utilizando esses argumentos, pois as ações pesquisadas se encontram em grau de recurso e, por essa razão, deve ser considerado o lapso temporal existente entre o ingresso da ação e o julgamento do recurso.

\section{REFERÊNCIAS}

APRILE, M. R.; BARONE, R. E. M. Educação superior: políticas públicas para inclusão social. Revista@mbienteeducação, São Paulo, v. 2, n. 1, p. 39-55, jan./jun. 2009.

AVRITZER, L.; MARONA, M. C. Judicialização da política no Brasil: ver além do constitucionalismo liberal para ver melhor. Revista Brasileira de Ciência Política, Brasília, DF, n. 15, p. 69-94, 2014.

BRASIL. Constituição 1988. Constituição da República Federativa do Brasil de 1988. Brasília, DF. Disponível em:

http://www.planalto.gov.br/ccivil_03/Constituicao/Constituicao.htm. Acesso: 20 jul. 2015.

BRASIL. Conselho da Justiça Federal (CJF). Jurisprudência consolidada do Tribunal Regional Federal da 1a Região. Justiça Federal. [199-?]. Disponível em:

http://www.cjf.jus.br/cjf. Acesso em: 12 out. 2015.

BRASIL. Decreto n. 6.096, de 24 de abril de 2007. Institui o Programa de Apoio a Planos de Reestruturação e Expansão das Universidades Federais (REUNI). Brasília, DF, 2007. Disponível em:

http://www.planalto.gov.br/ccivil_03/_Ato2007-2010/2007/Decreto/D6096. htm. Acesso em: 15 ago. 2015.

BRASIL. Decreto n. 7.234, de 19 de julho de 2010. Dispõe sobre o Programa Nacional de Assistência Estudantil (PNAES). Brasília, DF, 2010. Disponível em: http://www.planalto.gov.br/ccivil_03/_Ato2007-2010/2010/Decreto/ D7234.htm. Acesso em: 10 ago. 2015. 
BRASIL. Decreto-Lei n. 4.657, de 4 de setembro de 1942. Lei de Introdução às normas do Direito brasileiro. Disponível em:

http://www.planalto.gov.br/ccivil_03/decreto-lei/Del4657.htm. Acesso em: 27 ago. 2015.

BRASIL. Justiça Federal. Consulta processual. Tribunal Regional Federal da 1a Região. [199-?]. Disponível em:

https://processual.trf1.jus.br/consultaProcessual/. Acesso em: 20 jul. 2015.

BRASIL. Justiça Federal. AMS 00036068920054013300 . Consulta processual. TRF1. 2007. Disponível em:

https://processual.trf1.jus.br/consultaProcessual/processo.php. Acesso em: 20 jul. 2015.

BRASIL. Lei n. 9.394, de 20 de dezembro de 1996. Estabelece as Diretrizes e Bases da Educação Nacional. Brasília, DF, 1996. Disponível em: http://www. planalto.gov.br/ccivil_03/decreto-lei/Del4657.htm. Acesso em: 27 ago. 2015.

BRASIL. Lei n. 10.558, de 13 de novembro de 2002. Cria o Programa Diversidade na Universidade, e dá outras providências. 2002. Disponível em: http://www.planalto.gov.br/ccivil_03/LEIS/2002/L10558.htm Acesso em: 27 dez. 2014.

BRASIL. Lei n. 11.096, de 13 de janeiro de 2005. Institui o Programa Universidade para Todos - Prouni, regula a atuação de entidades beneficentes de assistência social no ensino superior; altera a Lei n. 10.891, de 9 de julho de 2004, e dá outras providências. 2005. Disponível em:

http://www.planalto.gov.br/ccivil_03/decreto-lei/Del4657.htm. Acesso em: 27 ago. 2015.

BRASIL. Lei n. 12.711, de 29 de agosto de 2012. Dispõe sobre o ingresso nas universidades federais e nas instituições federais de ensino técnico de nível médio e dá outras providências. 2012. Disponível em:

http://www.planalto.gov.br/ccivil_03/_ato2011-2014/2012/lei/l12711.htm. Acesso em: 27 ago. 2015. 
BRASIL. Ministério da Educação. Portaria n. 807, de 18 de junho de 2010. Institui o Exame Nacional do Ensino Médio (ENEM) como procedimento de avaliação cujo objetivo é aferir se o participante do Exame, ao final do ensino médio, demonstra domínio dos princípios científicos e tecnológicos que presidem a produção moderna e conhecimento das formas contemporâneas de linguagem. Disponível em:

https://www.legisweb.com.br/legislacao/?id=227492. Acesso: 20 jul. 2015.

BRASIL. Universidade de Brasília. Análise do Sistema de Cotas para Negros da Universidade de Brasília. Período: 2o semestre de 2004 ao 1ㅇ semestre de 2013. CESPEUNB. Brasília, DF, 2013. Disponível em:

http://docplayer.com.br/9361961-Analise-do-universidade-de-periodo-2o-semestre-de-2004-ao-1o-semestre-de-2013-apoio.html. Acesso em: 3 maio 2016.

BRASIL. Universidade Federal da Bahia. Resolução n. 1, de 26 de julho de 2004. Altera a Resolução 01/2002 do CONSEPE. Estabelece reserva de vagas na seleção para os cursos de graduação da UFBA realizada através do Vestibular. 2004. Disponível em: https://www.ufba.br/resolucoes/608\%3B?page=2. Acesso: 20 jul. 2015 .

BRASIL. Universidade Federal da Bahia. Resolução n. 3, 12 de novembro de 2012. Altera o art. 3o e o art. 5ㅇda Resolução n. 01/2004 do CONSEPE. 2012. Disponível em: https://www.ufba.br/resolucoes/608\%3B?page=2. Acesso: 20 jul. 2015.

CATANI, A. M. et al. Prouni: democratização do acesso às Instituições de Ensino Superior? Educar em Revista, Curitiba, n 28, p. 125-140, 2006.

CAÔN, G. F.; FRIZZO, H. C. F. Acesso, equidade e permanência no ensino superior: desafios para o processo de democratização da educação no Brasil. UFSJ Repositório, São João del-Rey, v. 19, n 2, p. 1-15, 2010. Disponível em: https://ufsj.edu.br/vertentes/vertentes_v._19_n._2.php. Acesso: 20 maio 2015.

CURY, C. R. J. A nova lei de diretrizes e bases da educação nacional: uma reforma educacional. Medo a liberdade e compromisso democrático: LDB e Plano Nacional da Educação. São Paulo: Editora do Brasil, 1997. p. 91-135. 
DE CARVALHO, C. H. A. Política para a Educação superior no governo Lula expansão e financiamento. Revista do Instituto de Estudos Brasileiros, São Paulo, n. 58, p. 209-244, 2014.

FERES JÚNIOR, J.; DAFLON, V.; CAMPOS, L. A. A ação afirmativa no ensino superior brasileiro. Levantamento das políticas de ação afirmativa (GEMAA), IESP-UERJ, Rio de Janeiro, 2011. p. 1-20.

GAVILANES, R. V. Hacia una nueva definición del concepto política pública. Desafíos, [s.l.], v. 20, p. 149-187, 2010.

HECLO, H.; WILDAVSKY, A. The private government of public money: community and policy inside British politics. Springer, 1981.

LIPSKY, Michael. Street-level bureaucracy: dilemmas of the individual in public service. Russell Sage Foundation, 2010.

MATLAND, R. E. Synthesizing the implementation literature: the ambiguity-conflict model of policy implementation. Journal of public administration research and theory, [s.I.], v. 5, n. 2, p. 145-174, 1995.

MATTOS, W. R. de. Cotas para afrodescendentes na Universidade do Estado da Bahia: uma breve exposição comentada. Ação afirmativa e universidade: experiências nacionais comparadas, 2006. p. 167-182.

MOROSINI, M. C.; FRANCO, M. E. D. P.; SEGENREICH, S. C. D. A expansão da educação superior no Brasil pós LDB/96: organização institucional e acadêmica. Revista Inter Ação, Goiás, v. 36, n. 1, p. 119-140, 2011.

MULHOLLAND, T. O sistema de cotas para negros na Universidade de Brasília Ação Afirmativa e universidade: experiências nacionais comparadas. In: JÚNIOR, João Feres; ZONINSEIN, Jonas. Ação afirmativa e universidade: experiências nacionais comparadas. Brasília, DF: UnB, 2006. p. 183-185.

PARADA, E. L. Introducción a las políticas públicas. Santiago, Chile: Fondo de Cultura Económica, 2002.

RANIERI, N. B. Hard-cases e leading-cases no campo do Direito à Educação: o caso das quotas raciais. Revista de Direito Educacional, São Paulo, v. 1, n. 1, p. 245-275, 2010. 
SANTOS, J. T. dos. Cotas nas universidades: análises dos processos de decisão. CEAO, Salvador, v. 202, p. 41-74, 2012.

SUBIRATS, J. Análisis de políticas públicas y eficacia de la administración. In: SARAVIA, Enrique; FERRAREZI, Elisabete. (org.). Políticas públicas. vol. 1. Brasília, DF: Enap, 2006. p. 199-218.

ORGANIZAÇÃO DAS NAÇÕES UNIDAS PARA A EDUCAÇÃO, A CIÊNCIA E A CULTURA (Unesco). Portal virtual. [2019]. Disponível em: http://www.unesco.org.br. Acesso em: 6 ago. 2019.

ZAGO, N. Do acesso à permanência no ensino superior: percursos de estudantes universitários de camadas populares camadas populares. Revista Brasileira de Educação, Florianópolis, v. 11, n. 32, p. 226-237, maio/ago. 2006.

WARDE, M. J. O Banco Mundial e as políticas educacionais. Curitiba: Cortez, 1996.

WEATHERLEY, R.; LIPSKY, M. Street-level bureaucrats and institutional innovation: Implementing special-education reform. Harvard educational review, Massachusetts, v. 47, n. 2, p. 171-197, 1977.

WINTER, S. C. Implementation perspectives: Status and reconsideration. In: PIERRE, B. Guy Peters Jon. The sage handbook of public administration. London: Sage. 2012. p. 265-278. 